\title{
The first isolation and molecular characterization of Toxoplasma gondii from horses in Serbia
}

Ivana Klun ${ }^{1}$, Aleksandra Uzelac ${ }^{1}$, Isabelle Villena², Aurélien Mercier ${ }^{3,4}$, Branko Bobić ${ }^{1}$, Aleksandra Nikolić1, Irena Rajnpreht ${ }^{1}$, Marieke Opsteegh ${ }^{5}$, Dominique Aubert ${ }^{2}$, Radu Blaga ${ }^{6}$, Joke van der Giessen ${ }^{5}$ and Olgica Djurković-Djaković ${ }^{*}$

\begin{abstract}
Background: Consumption of undercooked or insufficiently cured meat is a major risk factor for human infection with Toxoplasma gondii. Although horsemeat is typically consumed rare or undercooked, information on the risk of T. gondii from infected horse meat to humans is scarce. Here, we present the results of a study to determine the presence of $T$. gondii infection in slaughter horses in Serbia, and to attempt to isolate viable parasites.

Methods: The study included horses from all regions of Serbia slaughtered at two abattoirs between June 2013 and June 2015. Blood sera were tested for the presence of specific lgG T. gondii antibodies by the modified agglutination test (MAT), and samples of trypsin-digested heart tissue were bioassayed in mice. Cyst-positive mouse brain homogenates were subjected to DNA extraction and T. gondii strains were genotyped using 15 microsatellite markers (MS).

Results: A total of 105 slaughter horses were sampled. At the 1:6 cut-off $48.6 \%$ of the examined horses were seropositive, with the highest titre being 1:400. Viable parasites were isolated from two grade type mares; both parasite isolates (RS-Eq39 and RS-Eq40) were T. gondii type III, and both displayed an increased lethality for mice with successive passages. These are the first cases of isolation of T. gondii from horses in Serbia. When compared with a worldwide collection of 61 type III and type III-like strains, isolate RS-Eq39 showed a combination of MS lengths similar to a strain isolated from a duck in Iran, and isolate RS-Eq40 was identical in all markers to three strains isolated from a goat from Gabon, a sheep from France and a pig from Portugal. Interestingly, the source horses were one seronegative and one weakly seropositive.

Conclusions: The isolation of viable T. gondii parasites from slaughter horses points to horsemeat as a potential source of human infection, but the fact that viable parasites were isolated from horses with only a serological trace of $T$. gondii infection presents further evidence that serology may not be adequate to assess the risk of toxoplasmosis from horsemeat consumption. Presence of T. gondii type III in Serbia sheds more light into the potential origin of this archetypal lineage in Europe.
\end{abstract}

Keywords: Toxoplasma gondii, Horse, Serbia, Prevalence, Strain, Isolation, Genotyping, Microsatellite markers, Type III

\footnotetext{
* Correspondence: olgicadj@imi.bg.ac.rs

${ }^{1}$ National Reference Laboratory for Toxoplasmosis, Centre of Excellence for Food- and Vector-Borne Zoonoses, Institute for Medical Research, University of Belgrade, Dr Subotića 4, 11129 Belgrade, Serbia

Full list of author information is available at the end of the article
} 


\section{Background}

Toxoplasma gondii is considered one of the most successful parasites on Earth due to its omnipresence and widest array of hosts, including all mammals [1]. The genus comprises a single species infective for all hosts, with limited genetic diversity in Europe and North America where the majority of isolates belong to the clonal genotypes type II and III, with the predominance of type II $[2,3]$. However, a wider genetic diversity characterized by non-clonal, atypical strains is found in South America and Africa, and is thought to be related to the presence of diverse Felidae as the only definitive host in which sexual reproduction, and consequentially, genetic recombinations, occur $[4,5]$.

Human infection is widespread; it has been estimated that one third of the global population is infected [6]. However, infection is generally mild and self-limiting, except in population categories with an incompetent immune system, including the foetus and immunosuppressed individuals, in which it may cause life-threatening disease. Treatment options have not advanced much for decades and there is still no drug able to eliminate encysted parasites.

Consumption of undercooked or insufficiently cured meat is a major risk factor for human infection with $T$. gondii [7-11].

Horsemeat is typically consumed rare or undercooked, particularly in some European countries such as Italy and France [12]. Serbia used to be an important horse producer and exporter, but the production has been significantly decreasing over the last decades. Local consumption of horsemeat currently constitutes about 0.01 $\mathrm{kg}$ per capita per year [13]. The presence of $T$. gondii in main meat producing animals in Serbia has been well established [14-16], but for horses there are very few data [14], and moreover, horse meat or tissues have not yet been analysed. Several strains originating from patients, as well as from pigs, sheep, rodents and pigeons have been already isolated and genotyped [17-20]. Viable cysts have been shown to persist for many months in various organs in experimentally infected horses [21].

Here, we present the results of a study to examine the presence of $T$. gondii infection in slaughter horses in Serbia, and to attempt to isolate viable parasites.

\section{Methods}

\section{Study population and collection of samples}

The total number of horses in Serbia is around 15,000 [22], of which about 400 are slaughtered each year. While no abattoir exclusively slaughters horses, those that do, usually slaughter them at a rate of once to twice per week. In this study, samples were obtained from horses slaughtered in two abattoirs, one in Northern
Serbia and the other in the vicinity of Belgrade, between June 2013 and June 2015. The sampled materials included blood and heart tissue. The heart was chosen for sampling as it was identified as a predilection site [23]. Blood $(8 \mathrm{ml})$ was collected in sterile centrifuge tubes (with no additive) during exsanguination at the slaughter line. The apex portion of the heart (at least $300 \mathrm{~g}$ ) was collected into a sample bag. Each animal was designated with a unique ID number and the samples were labelled accordingly. Samples were transported on ice to the Serbian National Reference Laboratory for Toxoplasmosis (NRL Toxo) immediately after collection. Upon arrival, each blood sample was centrifuged at $800 \times g$ for $20 \mathrm{~min}$, and the collected sera were immediately frozen and kept at $-80{ }^{\circ} \mathrm{C}$ until testing for $T$. gondii antibodies. Heart tissue was processed immediately or kept at $+4{ }^{\circ} \mathrm{C}$ until processing the following day.

\section{Collection of zoographical data}

Data on horses were collected from the accompanying health certificates and included age, gender and region of origin of the animal. Horses were classified by age as yearlings (1-2 years), young (3-4 years) or adult (5-9 years old). The regions of origin included Northern, Western, Central and Eastern Serbia, and "not determined", for horses brought for slaughter by traders who kept them just for a short time after purchase. Determination of horse type or breed was based on direct observation of the horses prior to slaughter, and on interview of the horse trader when present; horses were classified as grade (no dominant breed trait; for general use or light work only), working (used for medium work, dominantly Bosnian horse or Nonius breed mixes), and working heavy-type cold blooded horses.

\section{Study design}

Horse sera were sent to the French National Reference Centre for Toxoplasmosis (NRC Toxo) laboratory in Reims, where they were tested for specific IgG $T$. gondii antibodies. Heart samples were processed (at Serbian NRL Toxo) by trypsin digestion, and the digests inoculated into mice for bioassay. Following a 6-week observation period, the mice were euthanized, and sera tested for $T$. gondii antibodies, while brains were examined microscopically for $T$. gondii cysts. If cysts were observed, a portion of the brain homogenate was saved for DNA extraction for genotyping, and the rest reinoculated into fresh mice for strain propagation. Finally, the DNA samples extracted from the mouse brain homogenates were sent to the Biological Resource Centre Toxoplasma (BRC) in Limoges for strain genotyping. 


\section{Serology}

T. gondii-specific IgG antibodies were detected by a modified agglutination test (MAT) as described by Desmonts and Remington [24], the antigen for which was prepared by NRC Toxo in Reims. Horse sera were tested at NRC Toxo, at starting dilutions of 1:6, 1:10 and $1: 25$, and two-fold dilutions thereafter if needed.

Mouse sera were tested at the NRL Toxo in Belgrade, using the same protocol, but starting at a 1:20 dilution.

\section{Trypsin digestion}

Heart tissue samples were trimmed to remove any excess fat and connective tissue, and cut into roughly $2 \times 2$ $\mathrm{cm}$ cubes. A total of $200 \mathrm{~g}$ of tissue was weighed out and coarsely blended in a food processor. The minced tissue was digested with $0.25 \%$ porcine trypsin (T4674, Sigma-Aldrich, St. Louis, MO, USA) in sterile saline (final volume of $300 \mathrm{ml}$ ), supplemented with $200 \times$ penicillin-streptomycin solution (PAA Laboratories $\mathrm{GmbH}$, Pasching, Austria), and $27 \mu \mathrm{g} / \mathrm{ml}$ amoxicillin (Hemofarm, Vršac, Serbia). The digestion was performed at $37{ }^{\circ} \mathrm{C}$ for $1.5 \mathrm{~h}$ with continuous stirring. Next, the suspension was filtered through sterile gauze; the flowthrough was collected and washed three times with sterile saline, in between centrifugations for $10 \mathrm{~min}$ at $1,800 \times g$ at $4{ }^{\circ} \mathrm{C}$. This resulted in a $3-10 \mathrm{ml}$ pellet. To prevent carry-over contamination during processing, knives, all utensils and the food processor were thoroughly washed between samples with a detergent solution, followed by decontamination with a $10 \%$ hypochlorite solution and finally rinsing with distilled water.

\section{Mice (for bioassay)}

For parasite isolation, female Swiss-Webster mice (Medical Military Academy Animal Research Facility, Belgrade) were used. Mice, weighing 18-20 g at the beginning of each experiment, were housed at the Institute for Medical Research Animal Research Facility at two per cage, and offered regular mouse feed and drinking water ad libitum. Naïve mice are occasionally examined for $T$. gondii infection at random for various purposes, and none were ever shown to be infected.

\section{Bioassay}

Bioassays were performed as described previously [25]. Briefly, $1 \mathrm{ml}$ of the heart tissue digest pellet supplemented with gentamicin was inoculated intraperitoneally (i.p.) into two naïve mice each per heart. Mice were monitored daily over a period of 6 weeks; peritoneal fluid of those that needed to be euthanized was examined for the presence of $T$. gondii tachyzoites, and microbiological culture of peritoneal fluid was performed. After 6 weeks mice were euthanized, blood samples taken for serology, and brains homogenized with 1 $\mathrm{ml}$ of saline each for cyst enumeration and, in case of positive findings, for DNA extraction, and subinoculation for further propagation. Cysts were counted under a phase-contrast microscope in four $25 \mu \mathrm{l}$ drops of the brain suspensions, giving a threshold sensitivity of our method of 10 cysts $/ \mathrm{ml}$ of brain homogenates. A bioassay was considered positive if at least one $T$. gondii cyst was detected in either mouse.

The remaining homogenate from cyst negative bioassays was frozen, while homogenates from cyst positive bioassays were prepared for per os inoculation into 4 naïve mice (2 to 5 cysts per mouse) for subsequent passage and strain genotyping.

The bioassay protocol used was approved by the State Ethics Committee (Veterinary Directorate of the Ministry of Agriculture and Environmental Protection of Serbia decision no. 323-07-02446/2014-05/1) and a local Ethics Committee (0313-1/11).

\section{DNA extraction and microsatellite analysis and Neighbour-joining clustering}

Strains which were successfully established after initial bioassay and 1st passage were genotyped using MS analysis. Briefly, total genomic DNA was extracted from 100 $\mu \mathrm{l}$ of mouse brain homogenates using the NucleoSpin ${ }^{\circ}$ Tissue (mini) kit (Macherey-Nagel, Düren, Germany), according to the manufacturer's instructions. The resulting gDNA was re-suspended in a total volume of $100 \mu \mathrm{l}$ of elution buffer and stored at $-20{ }^{\circ} \mathrm{C}$ until shipment to $\mathrm{BRC}$ in Limoges. The isolates were genotyped based on length polymorphisms of 15 MS markers distributed on 10 of 14 chromosomes, as described previously [26].

For comparison, we included the genotyping data of all 61 strains with type III or type III-like genotypes (only excluding clones, i.e. repeat genotypes within the same locality), available at the BRC from Limoges, collected in Europe, the Americas, Africa/Middle East and Asia/Oceania (see Additional file 1: Table S1), seven of which have not been published previously. These 61 strains were collected from different animal species, or were isolated from patients with congenital toxoplasmosis (CT) by the French NRC Toxo. An unrooted neighbour-joining tree was reconstructed from MS data with Populations 1.2.32 (http://bioinformatics.org/populations/) based on Cavalli-Sforza and Edwards chorddistance estimator [27] and generated with MEGA 6.05 (http://www.megasoftware.net/history.php).

\section{Statistical analysis}

For the analysis of serological results, 95\% confidence intervals were calculated. The influence of examined variables on $T$. gondii seropositivity was analysed by Chisquare test. The possible influence of age (expressed in 5 
two-year increments) on $T$. gondii seropositivity was analysed by Spearman's rank correlation.

The level of significance was 5\%. All statistics were performed using the SPSS version 11.5 statistical package (SPSS Inc., Chicago, IL, USA).

\section{Results}

The study series involved a total of 105 slaughter horses of both sexes ranging from 10 months to 9 years of age (mean $6.1 \pm 1.8$ years, median 6 years). The sampled population size represents over $13 \%$ of the estimated total number of horses slaughtered in Serbia during the sampling period. Seropositivity to $T$. gondii infection taking the lowest serum dilution (1:6) as the cut-off value was $48.6 \%(51 / 105)$, with the highest titre being 1:400 (Fig. 1). However, by raising the cut-off value to the $1: 25$ dilution, the seropositivity decreased to $12.4 \%(13 / 105)$.

Analysis of the zoographic variables showed that neither age group, gender, type/use, region nor slaughterhouse (place of sampling) had any influence on $T$. gondii seropositivity, as estimated at both the 1:6 (Table 1) and 1:25 cut-off (data not shown). The observed inter-regional differences (with the highest seropositivity recorded in Western Serbia) were not significant, presumably due to the small subgroups. There was no influence of age (rank) of the horses, either (Spearman rank correlation: $\rho_{(103)}=-0.0398, P=0.687$ ).

Bioassays were completed for 104 of the 105 horses, because in one bioassay both mice died on day 2 and 3 post infection, respectively, with large numbers of Streptococcus equi and Pseudomonas spp. bacteria cultured from the peritoneal exudates (pex). T. gondii tissue cysts were detected from two grade type mares of "undetermined" origin, slaughtered at the same abattoir but on different days. Interestingly, one of these tested negative for $T$. gondii antibodies, and the other was positive only at the 1:6 dilution (Table 2). All three mice harbouring detectable $T$. gondii brain cysts were seropositive at high titres ( $\geq 1: 5120$ ), while, conversely, no specific antibodies were detected in any of the mice from cyst-negative bioassays. Both strains (RS-Eq39 and RSEq40) were successfully passaged after initial isolation and have since been maintained at the NRL Toxo. Of note, both displayed an increased lethality for mice with successive passages. Although all mice inoculated with horse heart digests survived without clinical symptoms for 6 weeks while developing hundreds of cysts, mice started succumbing to the infection as of the first subsequent passage. The inoculum was thereafter lowered to 3 then 2 cysts for RS-Eq39, and to 4 and 3 cysts for RSEq40.

\section{Microsatellite analyses}

MS genotyping analysis showed both isolates to be type III. These strains were compared to a collection of 61 type III and type III-like strains available at the BRC from Limoges (Additional file 1: Table S1). The RS-Eq39 strain showed less frequent alleles for markers M48 and N61 than most type III strains isolated in Europe, and was most closely related to a strain isolated from a duck in Iran, IR-Duck38. The strain RS-Eq40 was identical to strains TgA105011 (goat from Gabon), TgA32122 (sheep from France) and TgPiPr14 (pig from Portugal) in all MS marker lengths (Additional file 1: Table S1). Figure 2 depicts an unrooted tree obtained by neighbour-joining analysis of the 63 strains.

Interestingly, both RS-Eq39 and RS-Eq40 differ from the other mentioned type III strain previously isolated from a pigeon in Serbia, RS-G13, which showed uncommon alleles for markers N60 and M102 with respect to

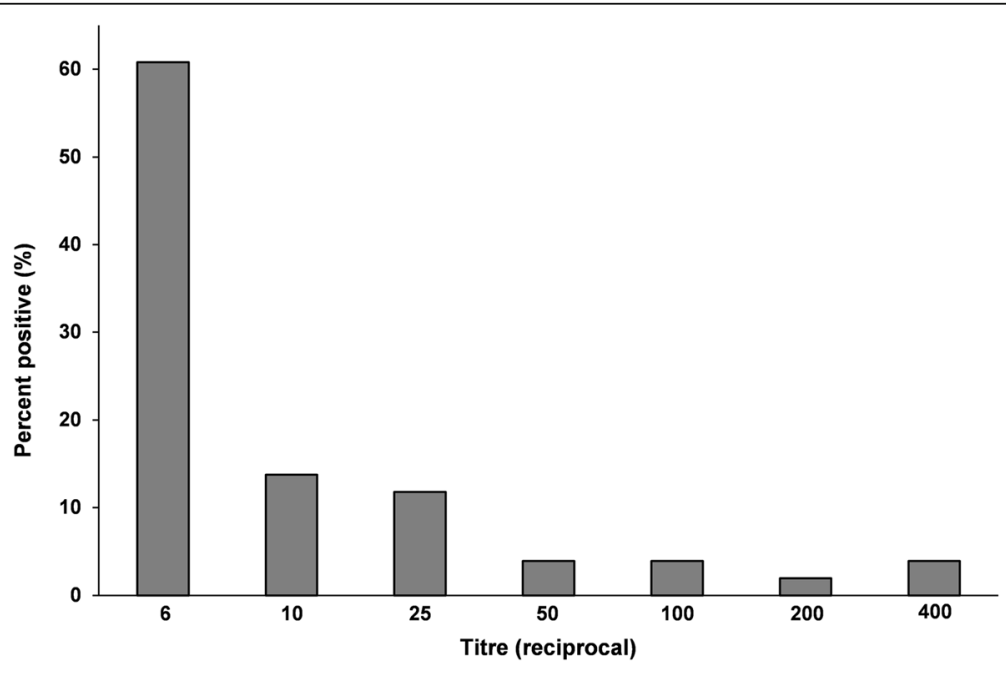

Fig. 1 Distribution of Toxoplasma gondii antibody levels in seropositive slaughter horses in Serbia 
Table 1 Toxoplasma gondii-specific antibodies as determined by the modified agglutination test (cut-off 1:6) in slaughter horses in Serbia according to zoographic characteristics

\begin{tabular}{|c|c|c|c|c|}
\hline Variable & $n$ & Seroprevalence (\%) & $95 \% \mathrm{Cl}$ & Chi-square $P$-value \\
\hline \multicolumn{5}{|l|}{ Age group } \\
\hline Yearling (1-2 years) & 4 & 25.0 & $0-67.4$ & \multirow[t]{3}{*}{0.309} \\
\hline Young (3-4 years) & 14 & 64.3 & $39.2-89.4$ & \\
\hline Adult (5-9 years) & 87 & 47.1 & $36.6-57.6$ & \\
\hline \multicolumn{5}{|l|}{ Gender } \\
\hline Female & 51 & 43.1 & $29.5-56.7$ & \multirow[t]{2}{*}{0.279} \\
\hline Male & 54 & 53.7 & $40.4-67$ & \\
\hline \multicolumn{5}{|l|}{ Type/use } \\
\hline Grade & 79 & 50.6 & $39.6-61.6$ & \multirow[t]{3}{*}{0.723} \\
\hline Working & 8 & 37.5 & $3.9-71$ & \\
\hline Working, heavy & 18 & 44.4 & $21.4-63.3$ & \\
\hline \multicolumn{5}{|l|}{ Region } \\
\hline Northern Serbia & 10 & 30.0 & $1.6-58.4$ & \multirow[t]{5}{*}{0.233} \\
\hline Western Serbia & 10 & 70.0 & $41.6-98.4$ & \\
\hline Central Serbia & 13 & 30.8 & $5.7-55.9$ & \\
\hline Eastern Serbia & 16 & 43.7 & $19.4-68.1$ & \\
\hline Undetermined/Traders' & 56 & 53.6 & $40.5-66.6$ & \\
\hline \multicolumn{5}{|l|}{ Slaughterhouse } \\
\hline A & 56 & 51.8 & $38.7-64.9$ & \multirow[t]{3}{*}{0.481} \\
\hline B & 49 & 44.9 & $31-58.8$ & \\
\hline Total & 105 & 48.6 & $39-58.1$ & \\
\hline
\end{tabular}

the other strains isolated in Europe and was actually most closely related to a strain isolated from a sheep in Iran (IR-Sheep68) (Fig. 2).

Comparative MS marker analysis of genotypes of all 63 type III and type III-like isolates from Europe, the Americas, Africa, Asia and Oceania (Additional file 1: Table S1) revealed 59 distinct genotypes. Of the 63 analysed strains, a total of three were isolated from horses, which, in addition to the two from Serbia, include an isolate from horsemeat (TgA21035) imported from Canada into France [28].

\section{Discussion}

This study showed a $T$. gondii seropositivity in horses from Serbia of almost $50 \%$ at a 1:6 MAT cut-off value, and $12.4 \%$ at $1: 25$ as the cut-off value. The value obtained at the 1:25 cut-off is significantly lower than the $30.8 \%$ seroprevalence found in an earlier study [14] (performed with the same test at the same cut-off) and probably reflects the difference in the age of the horses, since the animals in the present study were significantly younger $(P=0.00056)$. Worldwide, the reported seroprevalence in horses ranges from 0 to $100 \%$, and from 0 to $53 \%$ in Europe (rev. in $[29,30])$. Recent studies in Europe have shown seropositivity rates of $1.7 \%$ in Greece [31], 10.8\% in Spain [32], 3\% [33] and 17.6\% in Italy [34], 23\% in the Czech Republic [35], 37.8\% in Romania [36], and from 13 to $90 \%$ (depending on the cut-off) in France [37]. It is difficult to assess whether the reported data represent real differences in the seroprevalence of T. gondii infection or possibly reflect the use of different assays, different cut-offs for modified agglutination

Table 2 Source animal characteristics and strain mouse bioassay and genotyping results of the two Toxoplasma gondii strains isolated from the hearts of slaughter horses in Serbia

\begin{tabular}{|c|c|c|c|c|c|c|c|c|}
\hline \multirow[t]{3}{*}{ Gender } & \multirow[t]{3}{*}{ Age } & \multirow[t]{3}{*}{ Type/use } & \multirow[t]{3}{*}{ MAT (horse sera) } & \multicolumn{4}{|l|}{ Bioassay } & \multirow[t]{3}{*}{ Genotype } \\
\hline & & & & \multicolumn{2}{|l|}{ Mouse 1} & \multicolumn{2}{|l|}{ Mouse 2} & \\
\hline & & & & Brain cysts/ml & MAT & Brain cysts/ml & MAT & \\
\hline Mare & 6 & Grade & $<1: 6$ & 1010 & $1: 20480$ & 320 & $1: 20480$ & III \\
\hline Mare & 4 & Grade & $1: 6$ & 690 & $1: 5120$ & 0 & $<1: 20$ & III \\
\hline
\end{tabular}




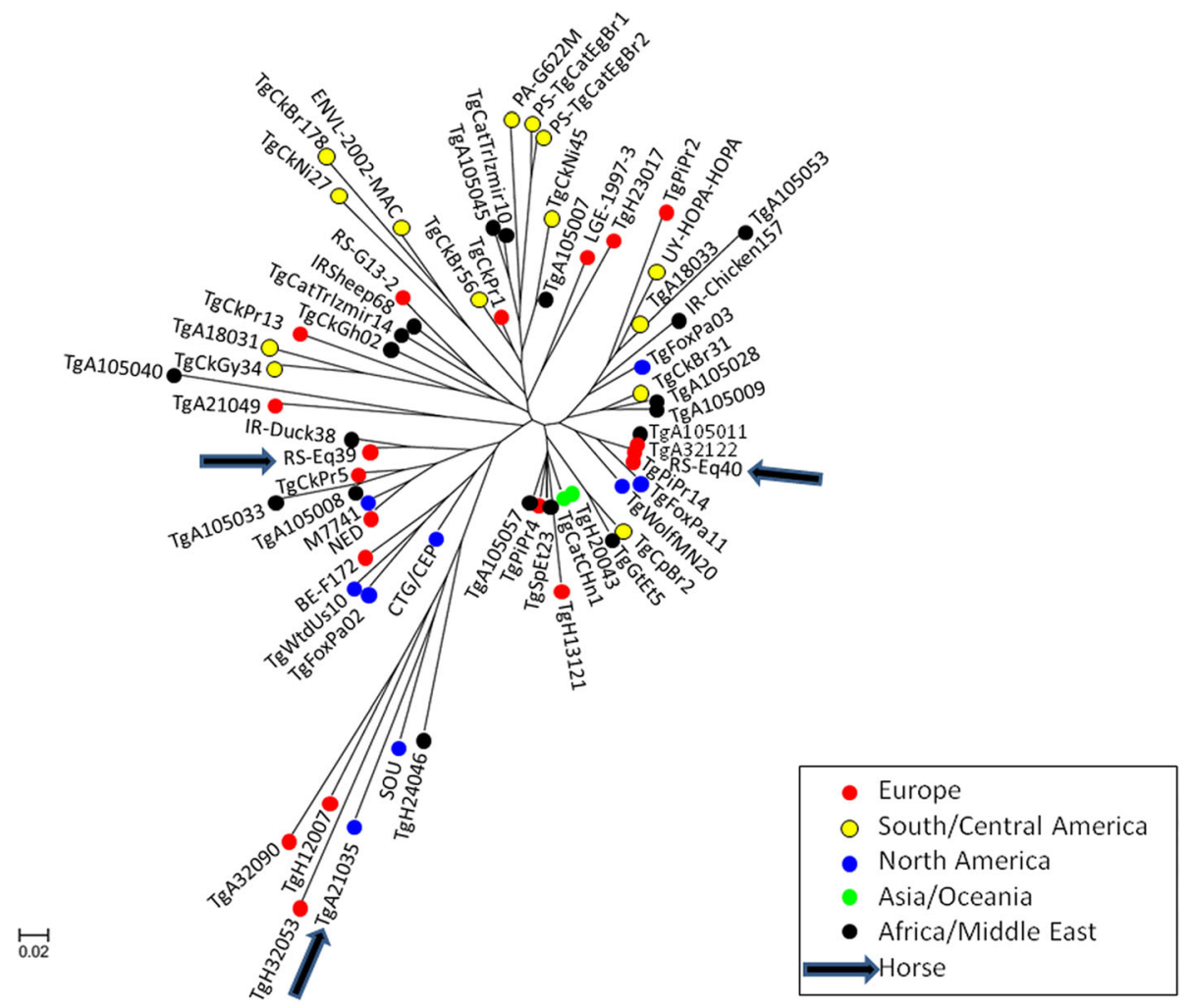

Fig. 2 Neighbour-joining clustering of Toxoplasma gondii isolates based on 15 microsatellite markers. Red points are for isolates from Europe ( $n=19)$; yellow points are for isolates from South and Central America $(n=14)$; blue points are for isolates from North America $(n=9)$; green points are for isolates from Asia and Oceania $(n=2)$; black points are for isolates from Africa and the Middle East $(n=19)$; arrows are for strains isolated from horses: two in this study (RS-Eq39 and RS-Eq40) and one in a previous study (TgA21035)

assays or perhaps intrinsic differences in the study samples regarding age and/or true origin of the animals.

Despite numerous serological data, reports of $T$. gondii isolations from naturally infected horses are quite rare. Interestingly, first isolations come from 50 years ago [38-40], but after a long gap, the last few years have seen a renewed interest in this issue. In Brazil, T. gondii was detected in the brains of $3.5 \%$ (14/398) horses by mouse bioassay, according to presence of parasites in two mice (in brain and pex one each) or mouse IFAT seropositivity alone (in 12 cases) [41]. In Europe, two strains have only recently been isolated from the hearts of seropositive slaughter horses in Romania (by mouse bioassay), but were not genotyped [36]. In Italy, Papini et al. [34] have isolated three strains and genotyping by PCR-RFLP showed them to be of type I, II/III and III respectively. The isolation of two viable $T$. gondii strains from slaughter horses in Serbia described here is the first report in this country. It is interesting that both isolates belong to type III.

Archetypal type III and type III-like strains or DNA have been obtained from animals and human CT cases in Europe, and throughout the world (Additional file 1: Table S1). The two strains from Serbian horses are of archetypal type III, with the RS-Eq40 isolate sharing an identical MS genotype with strains with a very different geographical origin, within or from out of Europe (Gabon: TgA105011, France: TgA32122, Portugal: TgPiPr14), while the RS-Eq39 was most closely related to a strain isolated from a duck in Iran, IR-Duck38 (Additional file 1: Table S1; Fig. 2). This observed similarity between geographically distant strains may reflect recent clonal expansions of the Type III. On the other hand, in comparison to the only other horse isolate TgA21035 (a type III-like, from Canada), our two strains show differences on even 6 MS markers (B18, M48, M102, N60, AA, N83), demonstrating a different origin of these strains.

A worldwide distribution of type III $T$. gondii strains may be attributed to the proposed ancestral nature of type III relative to the other archetypal lineages [42, 43]. In Europe type III has mostly been isolated in Mediterranean countries (Additional file 1: Table S1) [44-49]. Its more frequent representation in the Mediterranean perimeter is further suggested by the present isolation of type III strains from horses and a previous one from a feral pigeon in Serbia [20]. These findings point to the possibility of importation of strains, sometime in the 
distant past, perhaps originally from Africa, where type III is common both in urban and rural environments [3, 43]. Moreover, type III strains were isolated, more frequently than type II strains, from birds in Egypt and Iran $[50,51]$. It is therefore possible that migratory birds have contributed to the spread of type III T. gondii into Europe. A more recent factor that may facilitate the spread of $T$. gondii of different genotypes throughout the world is globalization of trade and transportation.

The results of this study also present interesting information on the virulence of the isolated type III strains. The isolates themselves were initially of a weakly virulent phenotype; such type III strains have been described in Gabon (TgA105011 equals GAB1-2007-CAP-AEG6 in Mercier et al. [43]) and French Guiana (A. Mercier, unpublished data). However, our horse isolates seem unique in that their virulence increased in subsequent oral passages. An increase in T. gondii pathogenicity in mice has been historically documented following frequent i.p. passage, notably with type III strains [52], but oral inoculation has frequently led to a decrease in virulence [25].

Data regarding the risk of transmission of $T$. gondii from infected horse meat to humans are scarce and inferred. In France, Pomares et al. [28] described three cases of human toxoplasmosis, in which MS genotyping showed all three to be different atypical strains, and epidemiologic explorations revealed that the probable source of infection was eating raw horsemeat, in two cases imported from Canada and Brazil, respectively. The risk was further emphasized by the isolation of a type III-like strain from horsemeat (originating from Canada) obtained from the first patient's butcher [28]. Using MC-PCR, Aroussi et al. [37] detected T. gondii DNA in $43 \%$ of 231 horsemeat samples from French supermarkets. Strain isolation was attempted from 118 samples by mouse bioassay, but no parasites were isolated, which the authors considered to reflect low distribution of cysts in skeletal muscles, therefore indicating a low risk of human $T$. gondii infection from consuming infected horsemeat [37]. However, quite the opposite was concluded in a study of the relative contribution of sheep, beef and pork products to human T. gondii infection in the Netherlands (as quantified by Quantitative Microbial Risk Assessment), which showed a high public health risk even in the case of low prevalence of parasite cysts in animal tissues, if the meat is inadequately processed [53]. Therefore, as horsemeat is generally consumed rare or undercooked, the risk for human infection may be high even in the case of low cyst burden in horse tissues.

In the case of isolations in Serbia, a low cyst burden may indeed explain the low isolation rate in view of the high seroprevalence, at least as estimated according to the low MAT cut-off [54]. However, a low cut-off of 1:10 was shown to give the best sensitivity/specificity balance between the MAT test and the presence of $T$. gondii DNA in meat samples as detected by MC-PCR [37]. Another important point is that the strains we isolated originated from one weakly seropositive animal and from another completely seronegative one. This, however, agrees with the results of a recent systematic review which has shown very low agreement between serological results and the presence of $T$. gondii cysts especially in large animals including cattle and horses, with a low recovery rate in seropositives and similar rates of direct detection of the parasite in seronegative and seropositive animals [23].

\section{Conclusions}

The isolation of viable T. gondii parasites from slaughter horses points to horsemeat as a possible and even probable source of human infection, a conclusion recently reached by a systematic review [55] as well. Moreover, successful isolations from horses with feeble serological evidence of $T$. gondii infection seem to confirm the notion [37] that the use of serological tests may not be recommended to assess the risk of human toxoplasmosis from consumption of horsemeat, which further limits the currently available tools to detect animals that may pose a threat to human health. Given that horsemeat tends to be consumed rare, the role of slaughter horses as sources of $T$. gondii infection should not be disregarded. Presence of T. gondii type III in Serbia sheds more light into the potential origin of this archetypal lineage in Europe.

\section{Additional file}

Additional file 1: Table S1. Genotyping data of 63 Toxoplasma gondii strains with type III or type III-like genotypes collected in Europe, the Americas, Africa, Asia and Oceania. (XLSX 19 kb)

\begin{abstract}
Abbreviations
95\% Cl: 95\% confidence interval; BRC: Biological Resource Centre Toxoplasma: CT: Congenital toxoplasmosis; DNA: Deoxyribonucleic acid;

i.p.: Intraperitoneal; IFAT: Immunofluorescence antibody test; MAT: Modified agglutination test; MC-PCR: Magnetic capture-polymerase chain reaction; MS: Microsatellite; NRC Toxo: National Reference Centre for Toxoplasmosis (France); NRL Toxo: National Reference Laboratory for Toxoplasmosis (Serbia); PCR-RFLP: Polymerase chain reaction-restriction fragment length polymorphism
\end{abstract}

\section{Acknowledgements}

Not applicable.

\section{Funding}

This study was conducted by a consortium within the framework of project $n^{\circ}$ GA/EFSA/BIOHAZ/2013/01 grant agreement, entitled "Relationship between seroprevalence in the main livestock species and presence of Toxoplasma gondii in meat", funded by the European Food Safety Authority. This publication is partly based on the results obtained in the framework of this project, published under the sole responsibility of the authors, and shall 
not be considered as an EFSA output. The study was also funded by the Ministry of Education, Science and Technological Development of Serbia (project No. III 41019).

\section{Availability of data and materials}

The datasets supporting the conclusions of this article are included within the article and its Additional file 1: Table S1.

\section{Authors' contributions}

ODjDj and IK conceived and designed the study and wrote the first draft of the manuscript. JvdG, RB and MO participated in the study design. AM participated in writing of the manuscript. The procedures were performed by IK and IR (sampling, trypsin digestion, mouse bioassays and serology), AU (DNA extraction), IV and DA (serology), BB and AN (microscopy - cyst detection), and $\mathrm{AM}$ (microsatellite genotyping). IK, AU, AM, and ODjDj analysed the data. JvdG, MO, RB, IV and DA critically revised the manuscript. All authors read and approved the final manuscript.

\section{Competing interests}

The authors declare that they have no competing interests.

\section{Consent for publication}

Not applicable.

\section{Ethics approval}

The bioassay protocol used was approved by the State Ethics Committee (Veterinary Directorate of the Ministry of Agriculture and Environmental Protection of Serbia decision no. 323-07-02446/2014-05/1).

\section{Publisher's Note}

Springer Nature remains neutral with regard to jurisdictional claims in published maps and institutional affiliations.

\section{Author details}

National Reference Laboratory for Toxoplasmosis, Centre of Excellence for Food- and Vector-Borne Zoonoses, Institute for Medical Research, University of Belgrade, Dr Subotića 4, 11129 Belgrade, Serbia. ${ }^{2}$ Centre National de Référence de la Toxoplasmose, Laboratoire de Parasitologie-Mycologie, CHU Maison Blanche, EA 3800 SFR CAP-SANTE, UFR Médecine Université de Reims Champagne-Ardenne, 45 rue Cognacq-Jay, 51092 Reims, France. ${ }^{3}$ INSERM, UMR_S 1094, Neuroépidémiologie Tropicale, Université de Limoges, 2 rue du Docteur Marcland, 87025 Limoges, France. ${ }^{4}$ Toxoplasma Biological Resource Center (BRC), Centre Hospitalier-Universitaire Dupuytren, 87042 Limoges, France. ${ }^{5}$ National Institute for Public Health and the Environment (RIVM), Antonie van Leeuwenhoeklaan 9, 3520BA Bilthoven, Netherlands. ${ }^{6}$ Ecole Nationale Vétérinaire d'Alfort, UMR BIPAR, ANSES, INRA, Université Paris-Est, Laboratoire de santé animale de Maisons-Alfort, Maisons-Alfort, France.

Received: 7 December 2016 Accepted: 23 March 2017

Published online: 04 April 2017

\section{References}

1. Tenter AM, Heckeroth AR, Weiss LM. Toxoplasma gondii: from animals to humans. Int J Parasitol. 2000;30:1217-58.

2. Ajzenberg D. Type I, strains in human toxoplasmosis: myth or reality? Future Microbiol. 2010;5:841-3.

3. Shwab EK, Zhu XQ, Majumdar D, Pena HF, Gennari SM, Dubey JP, Su C Geographical patterns of Toxoplasma gondii genetic diversity revealed by multilocus PCR-RFLP genotyping. Parasitology. 2014;141:453-61.

4. Sibley LD, Khan A, Ajioka JW, Rosenthal BM. Genetic diversity of Toxoplasma gondii in animals and humans. Philos Trans R Soc Lond B Biol Sci. 2009;364: 2749-61.

5. Su C, Khan A, Zhou P, Majumdar D, Ajzenberg D, Dardé ML, et al. Globally diverse Toxoplasma gondii isolates comprise six major clades originating from a small number of distinct ancestral lineages. Proc Natl Acad Sci USA 2012:109:5844-9.

6. Montoya JG, Liesenfeld O. Toxoplasmosis. Lancet. 2004;363:1965-76.

7. Desmonts G, Couvrer J, Alison F, Baudelot J, Gerbeaux J, Lelong M. Étude épidémiologique sur la toxoplasmose: de l'influence de la cuisson des viandes de boucherie sur la fréquence de l'infection humaine. Rev Fr Etud Clin Biol. 1965;10:952-8.
8. Bobić B, Jevremović I, Marinković J, Šibalić D, Djurković-Djaković O. Risk factors for Toxoplasma infection in a reproductive age female population in the area of Belgrade, Yugoslavia. Eur J Epidemiol. 1998;14:605-10.

9. Cook AJ, Gilbert RE, Buffolano W, Zufferey J, Petersen E, Jenum PA, et al. Sources of Toxoplasma infection in pregnant women: a European multicentre case-control study. Br Med J. 2000;15:142-7.

10. Bobić B, Nikolić A, Klun I, Vujanić M, Djurković-Djaković O. Undercooked meat consumption remains the major risk factor for Toxoplasma infection in Serbia. Parassitologia. 2007;49:227-30.

11. Jones $J \mathrm{~L}$, Dubey JP. Foodborne toxoplasmosis. Clin Infect Dis. 2012:55:845-51.

12. Boireau P, Vallee I, Roman T, Perret C, Mingyuan L, Gamble HR, Gajadhar A. Trichinella in horses: a low frequency infection with high human risk. Vet Parasitol. 2000;93:309-20.

13. Statistical office of the Republic of Serbia (RZS). The consumption of meat and meat products in Serbia - household budget surveys raw data (20032009). http://pod2.stat.gov.rs/ObjavljenePublikacije/G2010/pdf/G20105526. pdf. Accessed 19 Mar 2010

14. Klun I. Seroepizootiological study of Toxoplasma gondii infection in ungulates in Serbia. Belgrade: Master's thesis, University of Belgrade School of Veterinary Medicine; 2005

15. Klun I, Djurković-Djaković O, Katić-Radivojević S, Nikolić A. Cross-sectional survey on Toxoplasma gondii infection in cattle, sheep and pigs in Serbia: seroprevalence and risk factors. Vet Parasitol. 2006;135:121-31.

16. Klun I, Vujanić M, Yera H, Nikolić A, Ivović V, Bobić B, et al. Toxoplasma gondii infection in slaughter pigs in Serbia: seroprevalence and demonstration of parasites in blood. Vet Res. 2011;42:17.

17. Djurković-Djaković O, Klun I, Khan A, Nikolić A, Knezević-Ušaj S, Bobić B, Sibley LD. A human origin type II strain of Toxoplasma gondii causing severe encephalitis in mice. Microbes Infect. 2006:8:2206-12.

18. Vujanić M, Ivović V, Kataranovski M, Nikolić A, Bobić B, Klun I, et al Toxoplasmosis in naturally infected rodents in Belgrade, Serbia. Vector Borne Zoonotic Dis. 2011;11:1209-11.

19. Štajner T, Vasiljević Z, Vujić D, Marković M, Ristić G, Mićić D, et al. Atypical strain of Toxoplasma gondii causing fatal reactivation after haematopoietic stem cell transplantion in a patient with an underlying immunological deficiency. J Clin Microbiol. 2013;51:2686-90.

20. Marković M, Ivović V, Stajner T, Djokić V, Klun I, Bobić B, et al. Evidence for genetic diversity of Toxoplasma gondii in selected intermediate hosts in Serbia. Comp Immunol Microbiol Infect Dis. 2014;37:173-9.

21. Dubey JP. Persistence of encysted Toxoplasma gondii in tissues of equids fed oocysts. Am J Vet Res. 1985;46:1753-4.

22. Anon. Number of livestock and beehives, 2013-2015. In: Statistical Yearbook of the Republic of Serbia. Statistical Office of the Republic of Serbia (RZS). 2016. http://pod2.stat.gov.rs/ObjavljenePublikacije/G2016/pdf/G20162019. pdf. Accessed 15 Nov 2016.

23. Opsteegh M, Maas M, Schares $G$ and van der Giessen J on behalf of the consortium. Relationship between seroprevalence in the main livestock species and presence of Toxoplasma gondii in meat (GP/EFSA/BIOHAZ/ 2013/01). An extensive literature review. Final report. EFSA Supporting Publications. 2016:13. doi:10.2903/sp.efsa.2016.EN-996.

24. Desmonts $\mathrm{G}$, Remington JS. Direct agglutination test for diagnosis of Toxoplasma infection: method for increasing sensitivity and specificity. J Clin Microbiol. 1980;11:562-8

25. Djurković-Djaković O, Nikolić A, Bobić B, Klun I, Aleksić A. Stage conversion of Toxoplasma gondii $\mathrm{RH}$ parasites in mice by treatment with atovaquone and pyrrolidine dithiocarbamate. Microbes Infect. 2005;7:49-54

26. Ajzenberg D, Collinet F, Mercier A, Vignoles P, Dardé ML. Genotyping of Toxoplasma gondii isolates with 15 microsatellite markers in a single multiplex PCR assay. J Clin Microbiol. 2010;48:4641-5.

27. Cavalli-Sforza LL, Edwards AW. Phylogenetic analysis. Models and estimation procedures. Am J Hum Genet. 1967:19:233-57.

28. Pomares C, Ajzenberg D, Bornard L, Bernardin G, Hasseine L, Darde ML, Marty P. Toxoplasmosis and horse meat, France. Emerg Infect Dis. 2011;17:1327-8

29. Dubey JP, Beattie CP. Toxoplasmosis in equids. In: Toxoplasmosis of animals and man. Boca Raton: CRC Press; 1988. p. 143-6.

30. Dubey JP. Toxoplasmosis in horses (Equus caballus). In: Toxoplasmosis of animals and humans. 2nd ed. Boca Raton: CRC Press; 2010. p. 177-8.

31. Kouam MK, Diakou A, Kanzoura V Papadopoulos E, Gajadhar AA, Theodoropoulos G. A seroepidemiological study of exposure to Toxoplasma, 
Leishmania, Echinococcus and Trichinella in equids in Greece and analysis of risk factors. Vet Parasitol. 2010;170:170-5.

32. García-Bocanegra I, Cabezón O, Arenas-Montes A, Carbonero A, Dubey JP, Perea A, Almería S. Seroprevalence of Toxoplasma gondii in equids from Southern Spain. Parasitol Int. 2012;61:421-4.

33. Bártová E, Machačová T, Sedlák K, Budíková M, Mariani U, Veneziano V. Seroprevalence of antibodies of Neospora spp. and Toxoplasma gondii in horses from southern Italy. Folia Parasitol. 2015;6:62.

34. Papini RA, Buzzone G, Nardoni S, Rocchigiani G, Mancianti F. Seroprevalence and genotyping of Toxoplasma gondii in horses slaughtered for human consumption in Italy. J Equine Vet Sci. 2015;35:657-61.

35. Bártová E, Sedlák K, Syrová M, Literák I. Neospora spp. and Toxoplasma gondii antibodies in horses in the Czech Republic. Parasitol Res. 2010;107:783-5.

36. Paştiu Al, Györke A, Kalmár Z, Bolfă P, Rosenthal BM, Oltean M, et al. Toxoplasma gondii in horse meat intended for human consumption in Romania. Vet Parasitol. 2015;212:393-5.

37. Aroussi A, Vignoles P, Dalmay F, Wimel L, Dardé ML, Mercier A, Ajzenberg D. Detection of Toxoplasma gondii DNA in horse meat from supermarkets in France and performance evaluation of two serological tests. Parasite. 2015;22:14.

38. Zardi O, Sulli E, Venditti G, Giorgi G. Epidemiological studies on toxoplasmosis. Isolation of strains of Toxoplasma gondii from domestic animals. Nuovi Ann Ig Microbiol. 1964;15:545-51.

39. Munday BL. The epidemiology of toxoplasmosis with particular reference to the Tasmanian environment. Parkville: Doctoral thesis, University of Melbourne; 1970.

40. Al-Khalidi NW, Dubey JP. Prevalence of Toxoplasma gondii infection in horses. J Parasitol. 1979;65:331-4.

41. Evers F, Garcia JL, Navarro IT, Zulpo DL, Nino Bde S, Ewald MP, et al. Diagnosis and isolation of Toxoplasma gondii in horses from Brazilian slaughterhouses. Rev Bras Parasitol Vet. 2013;22:58-63.

42. Khan A, Taylor S, Ajioka JW, Rosenthal BM, Sibley LD. Selection at a single locus leads to widespread expansion of Toxoplasma gondii lineages that are virulent in mice. PLoS Genet. 2009;5, e1000404

43. Mercier A, Devillard S, Ngoubangoye B, Bonnabau H, Bañuls AL, Durand P, et al. Additional haplogroups of Toxoplasma gondii out of Africa: population structure and mouse-virulence of strains from Gabon. PLoS Negl Trop Dis. 2010;4, e876.

44. Fuentes I, Rubio JM, Ramirez C, Alvar J. Genotypic characterization of Toxoplasma gondii strains associated with human toxoplasmosis in Spain: direct analysis from clinical samples. J Clin Microbiol. 2001;39:1566-70.

45. Dubey JP, Vianna MC, Sousa S, Canada N, Meireles S, Correia da Costa JM, et al. Characterization of Toxoplasma gondii isolates in free-range chickens from Portugal. J Parasitol. 2006;92:184-6.

46. De Sousa S, Ajzenberg D, Canada N, Freire L, Da Costa JM, Darde ML, et al. Biologic and molecular characterization of Toxoplasma gondii isolates from pigs from Portugal. Vet Parasitol. 2006;135:133-7.

47. Antoniou M, Tzouvali H, Sifakis S, Galanakis E, Georgopoulou E, Tselentis Y. Toxoplasmosis in pregnant women in Crete. Parassitologia. 2007;49:231-3.

48. Messaritakis I, Detsika M, Koliou M, Sifakis S, Antoniou M. Prevalent genotypes of Toxoplasma gondii in pregnant women and patients from Crete and Cyprus. Amer J Trop Med Hyg. 2008;79:205-9.

49. Vilares A, Gargaté MJ, Ferreira I, Martins S, Júlio C, Waap H, et al. Isolation and molecular characterization of Toxoplasma gondii isolated from pigeons and stray cats in Lisbon, Portugal. Vet Parasitol. 2014;205:506-11.

50. Dubey JP, Graham DH, Dahl E, Hilali M, El-Ghaysh A, Sreekumar C, et al. Isolation and molecular characterization of Toxoplasma gondii from chickens and ducks from Egypt. Vet Parasitol. 2003;114:89-95.

51. Khademvatan S, Saki J, Yousefi E, Abdizadeh R. Detection and genotyping of Toxoplasma gondii strains isolated from birds in the southwest of Iran. Brit Poultry Sci. 2013;54:76-80.

52. Frenkel JK. Pathogenesis of toxoplasmosis and of infections with organisms resembling Toxoplasma. Ann NY Acad Sci. 1956;64:215-51.

53. Opsteegh M, Prickaerts S, Frankena K, Evers EG. A quantitative microbial risk assessment for meatborne Toxoplasma gondii infection in The Netherlands. Intl J Food Microbiol. 2011;150:103-14.
54. Opsteegh M, Schares G, Blaga R and van der Giessen J on behalf of the consortium. Experimental studies of Toxoplasma gondii in the main livestock species (GP/EFSA/BIOHAZ/2013/01). Final report. EFSA Supporting Publications. 2016;13. doi:10.2903/sp.efsa.2016.EN-995.

55. Belluco S, Mancin M, Conficoni D, Simonato G, Pietrobelli M, Ricci A. Investigating the determinants of Toxoplasma gondii prevalence in meat: a systematic review and meta-regression. PLoS ONE. 2016;11:e0153856.

\section{Submit your next manuscript to BioMed Central and we will help you at every step:}

- We accept pre-submission inquiries

- Our selector tool helps you to find the most relevant journal

- We provide round the clock customer support

- Convenient online submission

- Thorough peer review

- Inclusion in PubMed and all major indexing services

- Maximum visibility for your research

Submit your manuscript at www.biomedcentral.com/submit
) Biomed Central 